\title{
ПРЕДПОСЫЛКИ ВОССТАНОВЛЕНИЯ МЕЖДУНАРОДНОГО ТУРИЗМА В СТРАНАХ АРАБСКОГО МИРА
}

\section{(c) 2021 Гузикова Людмила Александровна}

доктор экономических наук, профессор Высшей инженерно-экономической школы Санкт-Петербургский политехнический университет Петра Великого, Россия, Санкт-Петербург E-mail: guzikova@mail.ru

\section{(C) 2021 Радван Юунан}

аспирант Высшей инженерно-экономической школы

Санкт-Петербургский политехнический университет Петра Великого, Россия, Санкт-Петербург E-mail: younan-r@hotmail.com

До пандемии Covid-19 международный туризм играл заметную роль в экономиках арабских стран. Цель настоящего исследования - оценить предпосылки восстановления международного туризма в этих странах на основе анализа тенденций и закономерностей предшествующего периода. Полученные результаты могут быть полезны исследователям проблем развития туризма и региональным политикам, отвечающим за развитие этой отрасли.

Ключевые слова: туризм, международный туризм, индекс конкурентоспособности в секторе туризма и путешествий, туристский поток, факторы туристского потока, Ближний восток и Северная Африка, арабские страны.

Регион Ближнего Востока и Северной Африки (БВСА) на протяжении всей истории человечества этот регион был важной частью маршрутов путешественников, и сегодня он продолжает оставаться центром туристской активности и путешествий [3]. Как пишет Д. Дж. Тимоти [12], регион БВСА обладает богатыми ресурсами, которые привлекают широкий спектр типов туристов, и сталкивается с проблемами, которые бросают вызов не только развитию туризма. Природные и культурные ценности региона привлекают различные категории туристов, но имеющийся потенциал БВСА еще не полностью используется [1], он частично оказался непригодным для использования или был безвозвратно уничтожен в результате беспорядков и войн [6]. Во многих странах региона структурные проблемы в туристической политике и экономике усугубляют ситуацию [11].

Большинство стран региона принадлежат к Арабскому миру, и в дальнейшем именно они будут объектом анализа.

Цель настоящего исследования заключается в выявлении предпосылок восстановления международного туризма в арабских странах на основе анализа тенденций, сложившихся в предшествующий период.

В годы, предшествовавшие пандемии Covid-19, туризм в регионе БВСА активно раз- вивался, и во многих странах успел стать одним из основных источников доходов, сферой занятости значительной и стратегическим компонентом диверсификации экономик, основанных на нефти. В 2018 году регион БВСА принял 87 миллионов международных туристов, что эквивалентно 6\% от общего числа прибытий в мире. Число международных туристских прибытий в направлениях в 2018 году по сравнению с 2017 годом выросло примерно на 10\%, что превышало средний мировой показатель роста. Из общего числа прибывших в страны БВСА почти три четверти (73\%) приходилось на Ближний Восток и около 27\% - на Северную Африку. В 2017 году регион заработал 77 млрд долларов США в виде поступлений от международного туризма, что составило примерно 6\% мировых доходов от туризма [13].

По прогнозам UN WTO, сделанным до пандемии, к 2030 году ежегодный туристский поток в регион БСВА должен был вырасти более чем до 150 миллионов туристов, а доля региона в мировом туризме - увеличиться до 8\% [13].

Международный туризм в регионе включает уже существующие и новые направления в Средиземноморье и на Аравийском полуострове [9]. Структура туризма по странам-дестинациям, принадлежащим к Арабскому миру, и регионам отправления показана в табл. 1. Следует отме- 
Таблица 1. Структура международного въездного туризма в БВСА

\begin{tabular}{|c|c|c|c|c|c|c|c|}
\hline \multirow{2}{*}{\multicolumn{2}{|c|}{$\begin{array}{l}\text { Международные туристские при- } \\
\text { бытия в } 2017 \text { году, тыс. чел }\end{array}$}} & \multicolumn{6}{|c|}{ Регион отправления (\%) } \\
\hline & & Африка & Америка & $\begin{array}{l}\text { Азия и } \\
\text { Океания }\end{array}$ & Европа & $\begin{array}{l}\text { Ближний } \\
\text { Восток }\end{array}$ & Иное \\
\hline \multicolumn{8}{|l|}{ Ближний Восток } \\
\hline Бахрейн & 4372 &.- & 0,4 & 0,7 & 2 & 96,8 & 0,1 \\
\hline Египет & 8157 & 9 & 5 & 8 & 48 & 28 & 0,3 \\
\hline Иордания & 3844 & 1,4 & 4 & 5 & 10 & 42 & 38 \\
\hline Кувейт & 203 & 1,4 & 2 & 29 & 3 & 63 & 0,4 \\
\hline Ливан & 1857 & 7 & 18 & 12 & 34 & 29 & 0,0 \\
\hline Оман & 2372 & 0.6 & 3 & 19 & 17 & 3 & 57 \\
\hline Палестина & 503 & 3 & 3 & 22 & 71 & 1 & \\
\hline Катар & 2256 & 4 & 7 & 29 & 21 & 38 & \\
\hline Саудовская Аравия & 16109 & 9 & 3 & 42 & 7 & 37 & 0,9 \\
\hline ОАЭ & 15790 & & & & & & \\
\hline \multicolumn{8}{|l|}{ Северная Африка } \\
\hline Алжир & 2451 & 48 & 0,5 & 3 & 15 & 3 & 30 \\
\hline Марокко & 11349 & 4 & 4 & 3 & 39 & 2 & 48 \\
\hline Тунис & 7052 & \begin{tabular}{l|l|}
37 & \\
\end{tabular} & 0,5 & 0,3 & 24 & 19 & 19 \\
\hline
\end{tabular}

*данные по Египту и Кувейту за 2016 год

тить, что на момент написания работы данные по некоторым странам отсутствовали, были неполными или запаздывали.

Из табл. 1 видно, что лидерами по числу прибытий были Саудовская Аравия и ОАЭ - высоко урбанизированные страны, привлекающие туристов как центры торговли и развлечений туризма. Страны «пляжного» туризма, такие как Египет, Марокко и Тунис значительно уступали им по величине туристского потока.

На рис. 1 показаны места стран Арабского мира в рейтинге ТTCI/ 2019 года, в который было включено 140 стран [14]. ТTСІ используется в качестве индикатора устойчивости при оценке конкурентоспособности в области путешествий и туризма [10]. В целом регион БВСА значительно повысил свою конкурентоспособность в области туризма, что отражает изменение положения субрегионов и отдельных стран в ТTCI. В 2018 году 12 из 15 стран БВСА, охваченных индексом, улучшили показатели по сравнению с предыдущим годом, благодаря чему регион опередил средние мировые показатели роста конкурентоспособности. Это тем более важно, так как совокупная доля туризма в региональном ВВП была выше, чем в других регионах мира. Регион БВСА

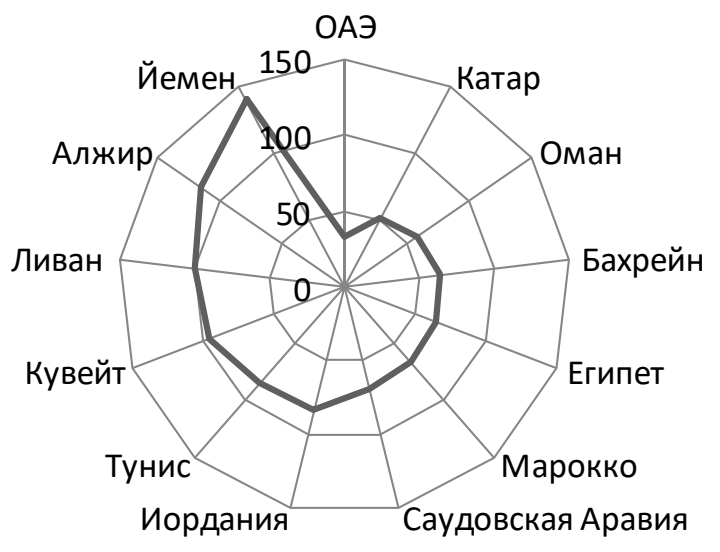

Puc. 1. Места стран БСВА в рейтинге ТТСI 2019 года 
также был единственным, где международные туристские расходы превышали внутренние. Несмотря на повышение конкурентоспособности и сильную зависимость общего экономического роста от туризма, средний показатель ТТСІ региона БВСА оставался ниже среднего глобального показателя.

Конкурентоспособность БСВА ниже среднемирового уровня является, главным образом, результатом низких показателей, связанных с природными и культурными ресурсами и международной открытостью. Историческое и религиозное наследие и географические особенности региона создают потенциал для значительного природного и культурного туризма, специфичного для региона исламского туризма $[4 ; 7 ; 8]$. Тем не менее, ни одна из стран БВСА не превышает среднемировой показатель по природным ресурсам. Количественные характеристики развития международного туризма в регионе отражены в табл. 2 .

В рамках исследования был предпринят анализ зависимости туристских прибытий в странах региона от уровня благосостояния стран, выраженного показателем ВВП на душу населения по паритету покупательной способности (ППП), и мощности туристской индустрии, выраженной числом занятых в ней работников. Установлено наличие корреляционной связи числа туристских прибытий с указанными величинами. Показатели корреляции равны 0,5649 0,6057, соответственно. Было построено регрессионное уравнение

$$
\mathrm{Y}=1918,1154+0,0019 * \mathrm{X}_{1}+0,0094 * \mathrm{X}_{2}+\varepsilon
$$

где Y - число туристских прибытий в страну, $\mathrm{X}_{1}-$ ВВП на душу населения по ППП, \$ тыс.;

$\mathrm{X}_{2}$ - число работников, занятых в туристской индустрии.

График фактических и расчетных значений (рис. 2) наглядно демонстрирует наличие зависимости, однако уровень детерминации построенного уравнения приводит к выводу, что в модель должны быть включены дополнительные параметры. Фактические значения заметно превышают расчетные для ОАЭ и Туниса. Значительное превышение расчетных значений над фактическими наблюдается для Египта и Саудовской Аравии.

В работе [2] был рассчитан показатель Хёрста для групп стран значение, отражающий постоянство международного туристского потока, то есть эмпирическую вероятность того, что возрастание туристского потока в прошлом ведет к его дальнейшему росту, и напротив, снижение потока в прошлом ведет к его дальнейшему снижению. Для стран Ближнего Востока этот показатель оказался выше соответствующих показателей для мирового и европейского туристских потоков.

В связи с пандемией Covid-19 в 2020 году туристская индустрия Арабских стран пережила глубокий кризис: снижение доходов отрасли и международный туристский поток сократились

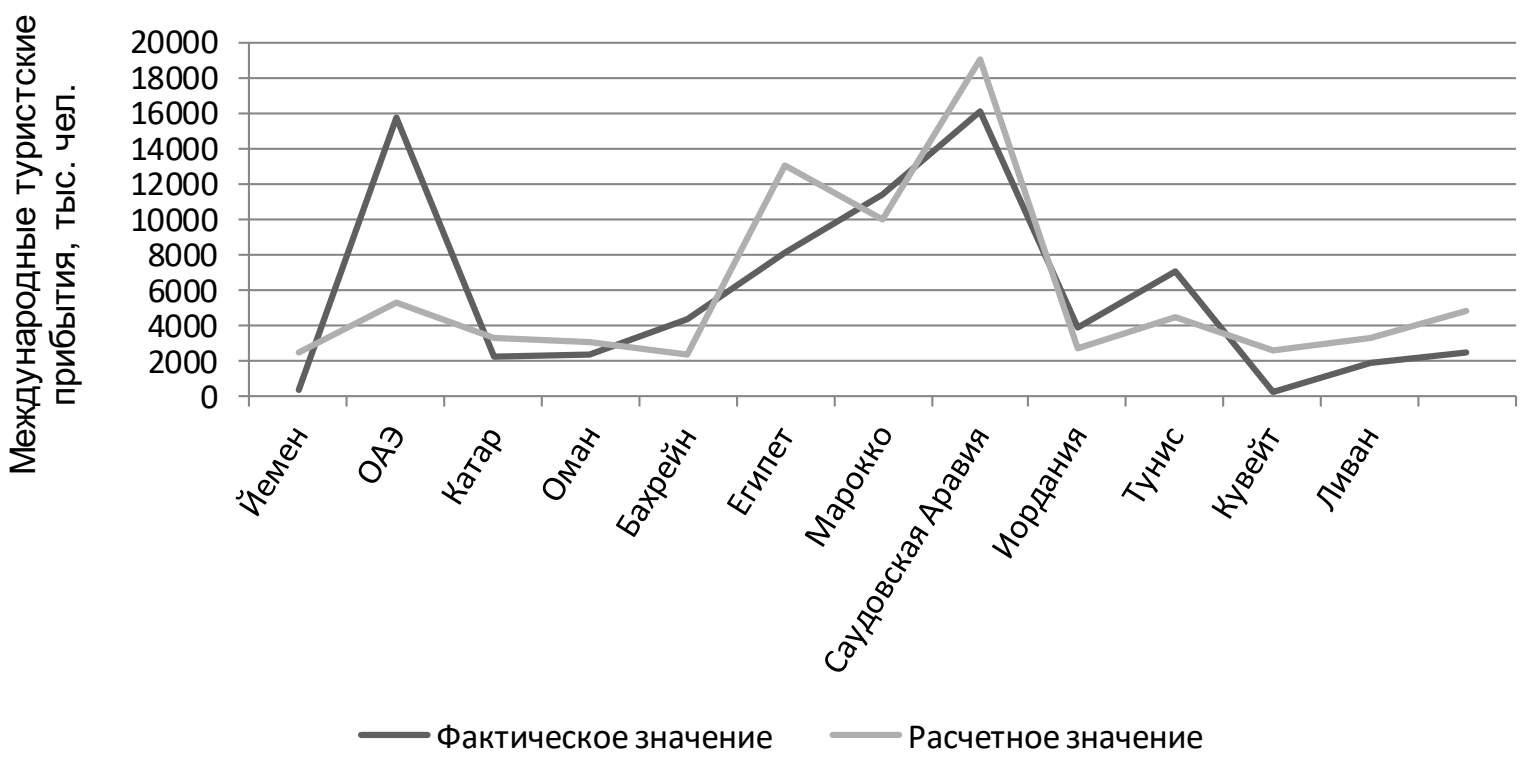

Puc. 2. Результаты моделирования числа туристских прибытий как функции доходов населения и мощности туристской индустрии 


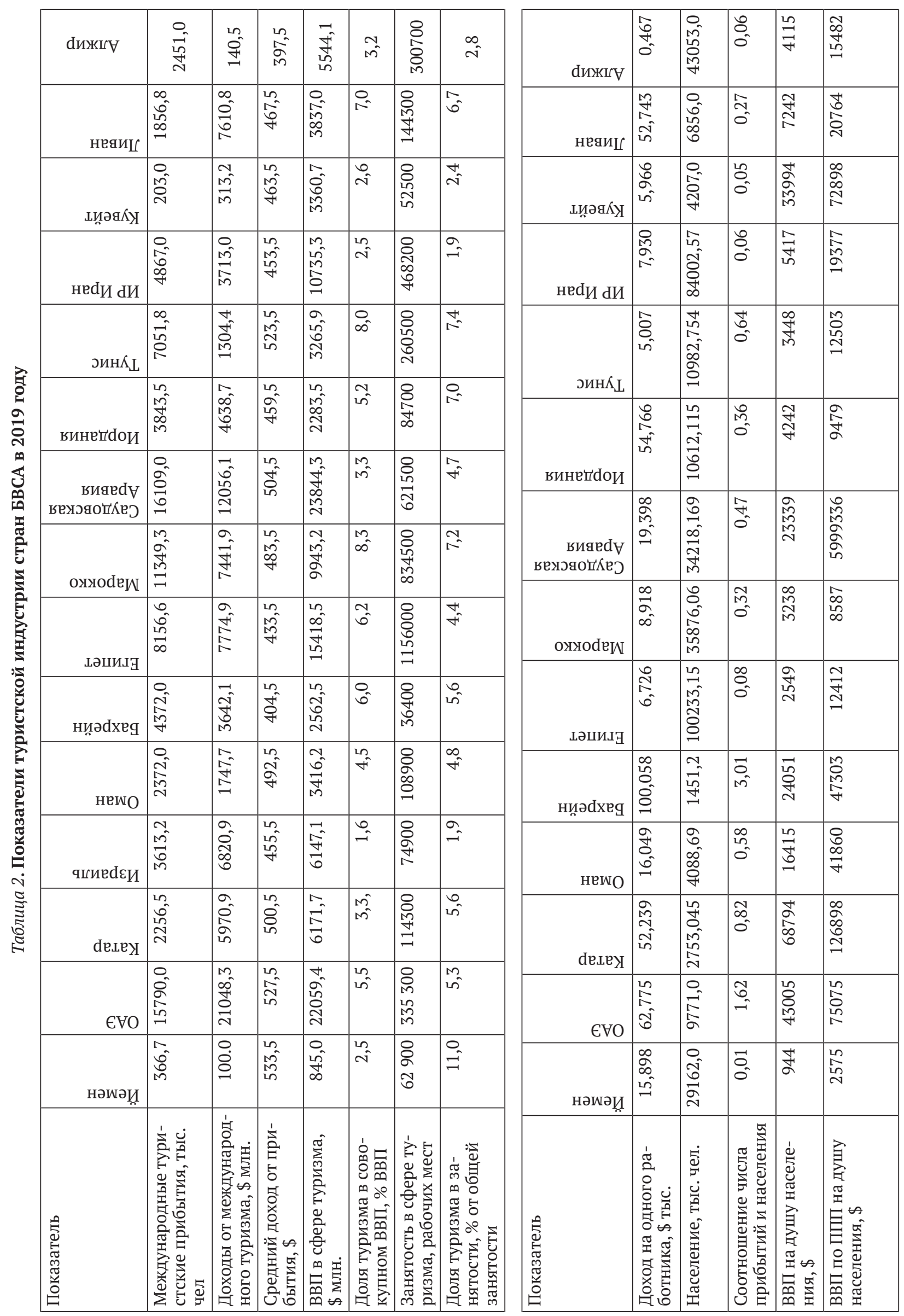


приблизительно на 70\%. Исследование Всемирного совета по путешествиям и туризму дает прогноз, что в 2021 году сектор путешествий и туризма на Ближнем Востоке должен вырасти на 27,1\% [15]. Это немного ниже среднемирового показателя, который составит 30,7\%. В [5] прогнозируется, что туристический сектор БВСА восстановится в краткосрочной и среднесрочной перспективе и достигнет 165 млрд долларов к 2025 году, что в четыре раза больше его доходов в 2020 году.

Проведенный анализ позволил сделать следующие выводы.

1. Для выявления предпосылок для восстановления туризма и дальнейшего развития турима в странах Арабского мира необходима надежная информационно-статистическая базы, которая позволила бы провести анализ прошлых тенденций и закономерностей и осуществлять планирование в будущем. Имеющаяся база нуждается в совершенствовании с точки зрения полноты и своевременности поступления информации.

2. Страны, являющиеся региональными лидерами урбанистического туризма (ОАЭ и Саудовская Аравия) значительно различаются по позициям в рейтинге конкурентоспособности TTCI, тогда как ведущие страны «пляжного» туризма (Египет, Марокко, Тунис) близки по своим позициям.

3. Для стран, лидирующих по числу туристских прибытий, имеются противоположные по направлению и значительные по величине расхождения между фактическими значениями туристского потока и расчетными значениями, полученными как линейная функция от уровня благосостояния стран и мощности туристской индустрии. Величина свободного члена в регрессионном уравнении может рассматриваться как автономный туристский поток, не зависящий от указанных факторов.

4. Значительная величина автономного туристского потока в сочетании с его персистентностью можно рассматривать как предпосылки для восстановления туризма в странах Арабского мира. По имеющимся оценкам, эти предпосылки могут быть реализованы и кризис в отрасли преодолен, для чего необходимо изыскивать новые инвестиционные возможности и разрабатывать меры организационно-технического характера.

\section{Библиографический список}

1. Насер Х.А. Проблемы и перспективы развития культурного и музейного туризма в странах «арабской весны» //Современные проблемы сервиса и туризма, 2016, 2(10), 72- 78.

2. Щелкунова Л.И., Емец М.С. Фрактальный анализ динамики международных прибытий в туризме //Бизнес информ. 2019. № 1 (492). С. 178-183.

3. Almuhrzi, H., Alriyami, H. \& Scott, N. (eds). 2017. Tourism in the Arab World. An Industry Perspective. Channel View Publications, Bristol, UK. 304 p.

4. Al-Hamarneh, A. \& Steiner, C., 2004. Islamic Tourism: Rethinking the strategies of tourism development in the Arab world after September 11th 2001. Comparative Studies of South Asia, Africa and the Middle East, 24(1), 173182.

5. Arabnews, 2021 https://www.arabnews.com/node/1927371/business-economy

6. Hopfinger, Hans and Scharfenort, Nadine. 2020. Tourism Geography of the MENA Region: Potential, Challenges and Risks: Editorial. Zeitschrift für Tourismuswissenschaft, 12 (2),. 131-157. https://doi.org/10.1515/tw-20200018

7. Kessler, K., 2015. Conceptualizing Mosque Tourism: A central feature of Islamic and Religious Tourism. International Journal of Religious Tourism and Pilgrimage, 3(2), 11-32.

8. Kovjanic, G., 2014. Islamic Tourism as a Factor of the Middle East Regional Development. Turizam, 18 (1), 33-43.

9. Mustafa, M. H., 2010. Tourism and Globalization in the Arab World. International Journal of Business and Social Science, 1, 37-48.

10. Ritchie, J.R. B., \& Crouch, G. I., 2003. The competitive destination, a sustainable tourism perspective, Cambridge: Cabi Publishing

11. Ruby, N., 1987. Tourism Planning. University Cultural Foundation, Alexandria, Egypt. [In Arab]

12. Timothy, Dallen J., 2019. Tourism Trends in the MENA Region. IEMed. Mediterranean Yearbook 2019, 322-325.

13. UNWTO, 2019, Tourism in MENA region. Published by the World Tourism Organization (UNWTO), Madrid, Spain. DOI: $10.18111 / 978-9284420896$

14. WEF https://reports.weforum.org/travel-and-tourism-competitiveness-report-2019/rankings/

15. WTTC, 2021. Middle East Travel \& Tourism sector set to recover by over a quarter this year https://wttc.org/NewsArticle/Middle-East-Travel-Tourism-sector-set-to-recover-by-over-a-quarter-this-year 